\title{
LA CRISIS DEL ORDEN COLONIAL. \\ ESTRUCTURA AGRARIA Y REBELIONES \\ POPULARES DE LA NUEVA ESPAÑA, 1750-1821 *
}

PEDRO PEREZ HERRERO

Universidad Complutense

Tradicionalmente la historia de México se ha venido interpretando como un proceso espacialmente homogéneo, sin importantes divisiones regionales e inscrito en una evolución de larga duración, que subrayaba el «desarrollo económico» y la estabilidad sociopolítica del siglo xvu, frente a la «crisis» y la *anarquia» de la primera mitad del siglo xIX. Esta interpretación enfatizaba el papel de las luchas de independencia como la causa principal de los «males» del México decimonónico: si México como nación no nacía o nacia cansada, hipotecada su economía y fragmentada su geografía a causa de las disensiones entre las élites locales en lucha por el control del poder (centralistas contra federalistas), se debía al alto costo pagado en estas guerras. Esta explicación se centraba en señalar que durante el proceso bélico las minas se inundaron, la infraestructura vial se arruinó, los capitales de los antiguos acaudalados comerciantes del Consulado de México huyeron con sus titulares tras el decreto de expulsión de los españoles a comienzos de la vida independiente, los campos y las cosechas heredaron una dinámica bélica y una gran mayoría de la población comenzó a ver más provechoso, rápido y fácil expoliar al vecino antes que acumular un capital mediante el lento trabajo cotidiano.

Existen varios factores que, unidos, produjeron esta imagen. La historiografía ilustrada del siglo xvil subrayó las excelencias del periodo en comparación con la época precedente de los Austrias. Durante este siglo, los historiadores soficialistas» se dedicaron en buena medida a probar que la nueva dinastía borbónica (vinculada al trono español desde comienzos del siglo XViI) y más particularmente Carlos III habian impulsado el crecimiento económico

* Eric Van Young, Alianza Editorial, México, 1992. 515 páginas. 
metropolitano y latinoamericano, habian conseguido un orden sociopolitico interno y habian extendido las «nuevas» ideas ilustradas. Al mismo tiempo ocultaron que se trataba de un proceso de centralización del poder y de una redefinición de las relaciones entre los territorios americanos y la metrópoli, ya que la dependencia y el colonialismo aumentaron sensible y progresivamente durante este siglo. Era evidente que para justificar una doctrina política como la del despotismo ilustrado se tenian que probar sus ventajas. El pueblo tenía que confiar en un monarca que trabajaba por el bienestar de sus súbditos. Por ello, no se escatimaron recursos ni esfuerzos para demostrar los beneficios del cambio borbónico.

La obra de A. de Humboldt puede tomarse como una de las representaciones más acabadas de esta interpretación triunfalista. El sabio alemán popularizó, utilizando la información oficial que virreyes y amigos le facilitaron, la visión de una Nueva España sumamente rica, primer productor mundial de plata, con una alta productividad agricola, un comercio exterior activo, unas finanzas publicas exuberantes y una población en crecimiento rápido y constante.

La historiografia liberal de la segunda mitad del siglo XIX repitió esta imagen de luces dieciochescas con el fin de poner de relieve que los liberales habían sido los responsables del despertar de México, de la superación del letargo de la primera mitad de este siglo. Si la historiografía borbónica se asentó en la comparación con la época austriaca del siglo xvil, creando la interpretación de la «crisis» de este siglo, la historiografía decimonónica utilizó la imagen en blanco y negro entre el acrecimiento del siglo xviII y la «depresión» de la primera mitad del xIx. Los historiadores conservadores, como Lucas Alamán, utilizaron el recurso de seguir fomentando las excelencias del periodo borbónico para alimentar sus proyectos políticos, al mismo tiempo que proteger sus ambiciones y negocios personales. Los historiadores porfirianos, como J. Sierra, trabajaron para demostrar cómo don Porfirio había traído la paz y el orden, y con ellos el bienestar y el progreso. No por casualidad desde mediados del siglo $\mathrm{xIX}$, con unas u otras intenciones, se comenzaron a imprimir o recuperar obras del siglo anterior que subrayaran los niveles de bienestar alcanzados durante los últimos riempos coloniales. El proyecto político colonial se repudiaba, pero se recordaba con añoranza el baile de los millones de los ingresos fiscales a fines de la colonia. Se interpretaba que el virreinato de la Nueva España habia seguido una carrera ascendente de mejora en sus condiciones económicas, sociales y politicas durante la segunda mitad del siglo xvin, y que durante la primera mitad del siglo siguiente lo que eran luces se convirtieron en sombras, el ascenso en descenso y el orden en continuos levantamientos, revueitas y pronunciamientos. 
Desde este punto de vista, era evidente que las guerras civiles independentistas debian mostrarse como esencialmente «destructivas», pero el problema surgía al intentar explicar la independencia política y los sangrientos movimientos sociales de finales de la época colonial partiendo de la idea de que se estaba pasando por uno de los mejores momentos de la vida del virreinato. La independencia se tenía que explicar, así, después de hacer dificiles equilibrios teóricos, como un movimiento de protesta contra un desigual reparto de la riqueza. El escollo siguiente era comprobar que en el periodo postindependentista inmediato no cambiaron ni la estructura económica (México siguió orientado hacia el exterior; Inglaterra sustituyó a España), ni la estructura interna de poder y el reparto de la riqueza, aunque sí cambió la justificación del mismo al no existir la corona española. La conclusión obvia era que si las guerras de comienzos del siglo XIX ganaron la independencia política, perdieron, sin embargo, el bienestar económico y social alcanzado a fines de la época colonial. La lección historiográfica era clara y políticamente peligrosa: sin «orden social» no había «progreso económico» y sin progreso no habria futuro. Porfirio Diaz y su política centralizadora, pacificadora y autoritaria era el ganador de la prueba histórica. Quedaba justificada una política represiva que garantizara el orden y la paz social. El «orden», evidentemente, era el de un México D.F. fuerte en el que los restantes estados miembros de la federación actuaran con la minima autonomía posible. La «paz» era impuesta por las armas. Porfirio Díaz era México, y México, Porfirio Díaz.

La presente obra de Eric Van Young, actualmente profesor de la Universidad de California-San Diego, rompe con algunas de estas clásicas interpretaciones, tomadas como válidas en muchas ocasiones por el simple hecho de su constante repetición acrítica. En la primera parte, titulada «Economía y sociedad en la Nueva España», se analizan tres aspectos de un mismo problema o si se prefiere un mismo problema desde diferentes puntos de vista: la agricultura novohispana de finales del siglo xvin. Se comienza con una perspectiva general de la situación del sector a fines de la época colonial, se continúa con un minucioso análisis de los cambios en la capacidad adquisitiva real del campesinado mexicano y se termina con un balance de la historiografia existente sobre el problema agrario y más específicamente sobre la hacienda.

Hasta ahora se pensaba que como consecuencia de las reformas borbónicas, el crecimiento de la producción minera, considerado como sector lider de la economia novohispana, había ocasionado un efecto de arrastre en el resto de los sectores económicos. Según esta tesis, este crecimiento significaba la mejora del conjunto de la economia. La consecuencia implícita inmediata de esta interpretación era concluir que los movimientos de independencia arruinaron 
la minería, con lo que el mágico «motor se arrastre» se paró, resquebrajándose el conjunto de la economía mexicana. La pretendida integración de los mercados internos dio paso a un proceso de regionalización profundo en el que cada mercado se replegó sobre si mismo.

Sin embargo, Eric Van Young pone de manifiesto que:

a) Los incrementos en la producción durante el siglo xvin pueden adscribirse a niveles más altos de inversión de capital $e$ insumos laborales en lugar de mejoras tecnológicas o a una nueva estructura productiva. El cambio inducido por la nueva política del reformismo borbónico en la agricultura fue minimo.

b) La hacienda mexicana ha sido una variable dependiente antes que una variable independiente, por lo que se ha venido estudiando equivocadamente la historia rural. Nunca entenderemos cabalmente la historia agraria mexicana hasta que dividamos nuestra atención entre la hacienda y otros elementos del campo y examinemos cuidadosamente la economía y sociedad rurales como un sistema en el que la propiedad rural sólo era una parte importante. Las haciendas, en contra de la creencia de la historiografia tradicional, tenían una marcada orientación hacia el mercado, mientras que los centros urbanos comenzaron a funcionar como el epicentro alrededor del cual giraba la integración interna socioeconómica de toda la región. Hay que aclarar, sin embargo, que esta orientación al mercado y la rentabilidad no eran necesariamente sinónimas. El hecho de que la hacienda mexicana no tuviera beneficios o que éstos fueran escasos no significaba necesariamente que en su administración no se tomara en cuenta la rentabilidad. Caracterizar la hacienda mexicana como «feudal» basándonos en su escasa orientación al mercado en ciertos lugares y épocas es confundir la causa con el efecto.

c) El crecimiento de la población en la Nueva España del siglo XVII, antes que el reformismo borbónico, parece que fue el gatillo que disparó un cierto grado de expansión económica, si bien al mismo tiempo impuso límites a la misma. El crecimiento de las ciudades mexicanas estimuló la división económica del trabajo dentro de la provincia y proporcionó simultáneamente importantes mercados para los productos agrícolas. Sin embargo, la misma expansión demográfica que ayudó a estimular la economía colonial, deprimiendo los niveles salariales y contribuyendo al crecimiento urbano, comenzó a fallar a fines del periodo colonial, como resultado de presiones malthusianas. Las tasas de crecimiento demográfico de comienzos del siglo xvm se convirtieron incluso en negativas en algunas regiones novohispanas en las últimas décadas del periodo colonial. En definitiva, la producción de plata no fue el único elemen- 
to integrador de los mercados internos, por lo que es evidente que si queremos comprender la atomización de la primera mitad del siglo XIX, debemos estudiar paralelamente la evolución de las demandas urbanas y las fluctuaciones demográficas.

d) Las presiones inflacionarias durante la segunda mitad del siglo xvIII, combinadas con el estancamiento en los niveles salariales nominales para una gran parte de la población económicamente activa, ocasionaron una caída en los salarios reales de manera más notable a fines del periodo colonial. La productividad agrícola creció poco durante el siglo xviı e incluso se estancó; los salarios agricolas reales decrecieron; y la escasez y el hambre se generalizaron, mientras se amplió la producción de las grandes unidades y se extendió la comercialización. Por tanto, no es casual encontrar que en contra de las expectaciones de los reformistas borbónicos, que pretendian ampliar los mercados internos latinoamericanos a las manufacturas españolas, los campesinos prefirieran ampliar sus niveles de subsistencia y optaran por los pagos en especie, antes que en moneda devaluada. Asi, parece evidente que, aun teniendo en cuenta que no se habia alcanzado un alto nivel de monetizacion en la economia novohispana, los estándares de vida en general de los trabajadores declinaron tanto en términos relativos como absolutos. El empobrecimiento de las áreas rurales resultante fue un elemento subyacente en la participación popular en la fase temprana de la lucha de independencia, siendo al mismo tiempo un síntoma de problemas económicos significativos de naturaleza estructural.

e) Finalmente, parece obvio que el corte cronológico impuesto por la historia política en 1810-1821 no tiene mucha relevancia para el estudio de los problemas agrarios. Todo parece indicar que la contracción económica postcolonial debió de iniciarse antes de 1810 . Por ello, descomponer en partes la tendencia (terminar o comenzar el estudio en 1810-1821) equivale a perder el significado del panorama global en aras de una claridad falsa. Lo importante no es la división, sino la continuidad. El ascenso de los criollos al poder no alteró las relaciones de producción rurales. El poder social y político y las ideas relativas al estatus y la jerarquía se mantuvieron ligados intimamente al control de la tierra por lo menos hasta la revolución de 1910. Las élites locales que dieron lugar a una estructura caciquil regional no se originaron por generación esPontánea en 1810, sino que eran la continuación de estructuras de poder regionales creadas y conservadas alrededor de los cabildos. Una de las pretensiones de las guerras de independencia fue recobrar la autonomía local que los borbones habian restringido. Por tanto, dividir el estudio de la historia rural mexicana en particular y del virreinato en general a partir de la indepen- 
dencia nacional es aplicar criterios incongruentes $e$ inadecuados al problema de la periodización histórica.

Estas nuevas interpretaciones son básicas, según Eric Van Young, para comprender de forma acertada el claroscuro del siglo xviII y los problemas del XIX. El crecimiento de la demanda urbana y de la población indigena significó un enfrentamiento entre las haciendas y las comunidades indigenas, dando lugar a una variación en las relaciones de producción existentes hasta el momento. El bienestar de unos significaba la pobreza de otros. La desigual distribución de la riqueza desempeñó un papel importante como precondición de la rebelión rural. No es en absoluto casual, por tanto, que el autor comience con una frase que está presente explicita o implícitamente a lo largo de todo el libro: «El siglo xvil fue, para México, una era de paradoja. En un período de esplendor barroco - cuyos testigos son aquellos suntuosos monumentos del estilo churrigueresco: Santa Prisca, Tepotzotlán, La Valenciana- el lépero se convirtió en una figura bien conocida en las calles de la capital virreinal». Vamos comprobando, pues, que el siglo xviII no era tan luminoso, ordenado y productivo como ilustrados y porfiristas nos habian hecho creer.

En la segunda parte del libro, el autor ofrece un interesante cambio de perspectiva. Partiendo de la evidencia de la profunda diversidad regional mexicana y por tanto de la peligrosidad de cualquier generalización, dadas las profundas divergencias en los procesos históricos locales, se enfoca ahora el análisis al caso concreto de la región del occidente de México.

De la mano del caso de Guadalajara, Eric Van Young revisa minuciosamente algunas de las implicaciones del modelo dualista-dendrítico, que defiende la tesis de que en América Latina existian dos sectores bien diferenciados: uno era el formado por los centros urbanos, compuestos mayoritariamente por una población blanca y/o mestiza, y caracterizados por una mayor modernidad, con relaciones de tipo capitalista y por tanto con una economía monetarizada y con una extensión del asalariado. El otro sector era el rural, precapitalista, etiquetado como atrasado, de autoconsumo, indigena y tradicional. Este modelo sostiene que ambos sectores se encontraban desconectados entre sí, vivian de espaldas mutuamente, hasta que los centros urbanos se convertian en motores del desarrollo, impulsando el cambio en sus binterlands rurales respectivos. En consecuencia, los sectores precapitalistas se convertian en capitalistas. El proceso de modernización se iba extendiendo con epicentro en aquellos puntos centrales de la economía capitalista, como los centros urbanos, reales de minas o centros de importación-exportación. Cada región se conectaba con los mercados exteriores y rara vez entre si. 
Las conclusiones a las que llega Eric Van Young son las siguientes:

a) Cuando se enfoca al mismo tiempo el estudio de los mercados urbanos y de sus binterlands rurales, se descubre una estructura regional mucho más compleja y rica de lo que se pudiera esperar al hacerlo por medio del modelo dualista. La producción agricola y el consumo urbano se habian analizado de forma disociada, con lo que se rompian sus lazos de interdependencia. Por ejemplo, se puede observar que el crecimiento de la población de la ciudad de Guadalajara durante la segunda mitad del siglo xvil fue causa y efecto de una complejización en la relaciones campo-ciudad. Este crecimiento de la demanda urbana alentó y expandió la agricultura comercial, desplazando en parte a la ganadería hacia zonas más alejadas. La tierra se convirtió en un factor de producción progresivamente valioso. No por casualidad, el área del Jalisco central pasó a ser la región abastecedora del creciente mercado urbano de Guadalajara. Esta expansión, como efecto de rebote, alentó a su vez las inversiones de capital (obras de riego y almacenaje) en las haciendas trigueras y maiceras de los alrededores de la ciudad, y, como consecuencia, las haciendas comerciales trigueras se expandieron sobre los antiguos pequeños productores maiceros. Lo que es importante subrayar es que este aumento de la producción triguera se llevó a cabo a través de una expansión de la agricultura tradicional y no como resultado de variaciones revolucionarias en las relaciones de producción. El cambio fue cuantitativo y no cualitativo. El aumento en la comercialización de la agricultura durante la última parte del periodo colonial fue sólo un ajuste de los factores de producción más que una innovación en la tecnologia agricola, puesto que la oferta de granos y sus precios estaban sujetos a fluctuaciones estructurales debidas a los sistemas de cultivo y mercado.

En definitiva, el autor puntualiza que seria más exacto utilizar para la comprensión de la integración espacial interna de la región de Guadalajara el modelo del sistema solar antes que el dendrítico. Por solar se entiende la estructura interna de una región compuesta por un centro y sucesivos satélites y subsatélites de éstos girando alrededor, formando una compleja y cruzada trama de relaciones.

b) Con respecto a la producción maicera, se observa una gran participación de los pequeños propietarios durante el siglo xviII, aunque también es verdad que paulatinamente fueron siendo desplazados por los grandes. A principios de siglo, la participación indigena en el abasto urbano era importante. Los pequeños productores lanzaban al mercado su producción en los meses inmediatos a la cosecha por no tener almacenes y necesitar de dinero en efectivo, mientras los grandes productores se iban apoderando del mercado con- 
forme escaseaba el producto y subía el precio. Los indios tenian que pagar sus tributos en efectivo, los arrendatarios sus alquileres y los comerciantes las deudas. Hasta 1780, por tanto, la agricultura indigena produjo un excedente maicero importante, subrayándose con ello la imposibilidad de la aplicación de las tesis dualistas. Sin embargo, el continuo crecimiento de la población indigena y la lucha por la tierra cultivable entre los indios y otros sectores de la población provocaron que el maiz producido fuera consumido localmente y que en raras ocasiones el grano arribara hasta la ciudad. Con la disminución de su capacidad productiva, los indios se vieron obligados a reingresar en la economía monetaria vendiendo su fuerza de trabajo. En definitiva, pues, la estructura socioeconómica del campo mexicano y las relaciones campo-ciudad eran más complejas de lo se habia mantenido hasta el momento.

c) Las relaciones entre el sector comercial y la economía campesina son bastante más complicadas de lo que proponen las tesis dualistas. Los pequeños rancheros, muchos de ellos arrendatarios antes que minifundistas independientes, desempeñaban un papel directo e indirecto en estas relaciones. Ellos mismos proveian de mano de obra para las actividades agrícolas de las haciendas a cambio de salarios en efectivo o como pago de su renta. A finales del siglo xvill se dio un cambio por parte de algunos hacendados para convertir el arrendamiento con pago de renta en arrendamiento por servicios. Los pequeños comerciantes de la región o los rancheros que actuaban como tales, en tanto proveían de crédito y vendían bienes a la población rural, funcionaban como intermediarios entre ambos mundos. Los pequeños agricultores (en tierras propias o arrendadas) producian gran parte de la fruta, verduras, productos de pan llevar y ganado menor (cerdos, cabras, gallinas, etc.) que se consumian en la ciudad de Guadalajara y en los pueblos del interior. Estos sectores, que Eric Van Young denomina «sectores medios rurales», cumplian la función amortiguadora entre la masa de pobladores rurales y la civilización urbana. En definitiva, se puede concluir que para el caso concreto del área de Guadalajara a fines del período colonial, el capitalismo agrario pudo tolerar, y aun estimular, la existencia de un modelo de producción distinto, parcialmente a través de la mediación de grupos sociales y económicos intersticiales. El problema para el campesino en esta situación era mantener su identidad; para el sector capitalista agricola, representado por la gran hacienda, era crear un proletariado rural. No debe sorprendernos, por tanto, que las dos metas resultaran incompatibles a la larga.

d) Las comunidades indias terratenientes, a partir de mediados del siglo xviI, tuvieron que soportar una intensificación de las presiones en contra de la preservación de su integridad como unidades sociales. A medida que crecía la 
población de los pueblos, la economía campesina de subsistencia empezó a toparse con las fronteras relativamente inelásticas de los recursos de la tierra y declinó el acceso per cápita a los campos agricolas. La distribución de riqueza dentro de los pueblos indios se hizo más marcada hacia ciertos individuos, entre los que se encontraban los notables y aquellos indios relacionados con la sociedad blanca. El calentamiento creciente de la economía en las comunidades produjo tensiones intragrupales que amenazaban con terminar en un conflicto social abierto.

Las disensiones con el exterior reforzaron las divisiones internas basadas en la clase y la etnicidad, fomentándose con ello el prejuicio social. La vida fuera del pueblo, si bien socavaba la autonomía productiva de los campesinos indios, también trajo consigo la liberación de algunas obligaciones destructivas de la comunidad. Las ventajas de permanecer dentro de la estructura formal de ésta eran superadas por las pérdidas en los excedentes o en los servicios. Ello no significó que las élites de los pueblos que presenciaban el vaciamiento de sus comunidades no cedieran sin luchar.

e) Los pueblos indios, en contra de lo que pudiera pensarse siguiendo los planteamientos clásicos dualistas, a pesar de recibir presiones de todos los frentes, lograron mantener sustancialmente su identidad como entidades socioeconómicas durante el siglo XIX y en muchas instancias durante el siglo xx. La defensa de la tierra fue uno de los mecanismos más importantes para asegurar que la condición del indio que vivia en el pueblo no cambiara de campesino a proletario rural. El conflicto por la tierra entre indios y no indios sirvió para expresar de una manera formal, institucionalizada, las tensiones raciales y sociales endémicas existentes. Como producto lateral de estas tensiones, el pueblo se hizo solidario. Al asumir una posición colectivamente agresiva hacia los de afuera, la comunidad definía sus nexos internos, al mismo tiempo que ayudaba a concretar su identidad. En definitiva, el autor interpreta que la lucha por la tierra era una estrategia compensatoria que trataba de reciclar las tensiones internas hacia el exterior y a través de la que las élites del pueblo recobraban parte de su erosionada autoridad.

La tercera parte del libro analiza algunos argumentos que habian surgido en las secciones precedentes. En ella se enfoca directamente el problema de la interpretación de los movimientos sociales de comienzos del siglo xIx. Tradicionalmente, con el fin especifico de reafirmar la identidad de México como nación, se habian venido subrayando los aspectos politicos de las guerras de independencia, por lo que un amplio porcentaje de la historiografia mexicanista habia repetido una y otra vez las gestas de los héroes independentistas, con- 
sideradas como la forja de la patria mexicana. Sin embargo, cuando se comienzan a estudiar dichos movimientos más de cerca, se comprueba su carácter mayoritariamente rural. Eric Van Young responde en esta sección a todo un abanico de preguntas con respecto a los antecedentes sociales, extensión, sentido de la oportunidad, metas y significación de dichos movimientos sociales. Entre las conclusiones más importantes caben destacarse las siguientes:

a) La acción violenta a gran escala de la población rural en contra de la autoridad constituida no era nueva ni rara en el México colonial, así como tampoco es cierto que los problemas sociales desaparecieran entre 1810 y el inicio de la Revolución de 1910. En tanto que levantamiento rural, la rebelión de 1810 tuvo unas caracteristicas ostensiblemente únicas y distintivas de los movimientos anteriores y posteriores. El carácter sostenido de las propuestas, su extensión espacial y numérica y sus metas políticas claramente sobrepasan la estructura de cualquier «rebelión campesina».

b) Para lograr una comprensión ajustada de la realidad, se debe hacer un estudio regionalizado a fin de reproducir correctamente la diversidad del fenómeno, puesto que las condiciones especificas de cada región hacen que no se pueda extraer una conclusión generalizable. A ello hay que añadir que los movimientos de independencia abarcaban distintos grupos sociales, cada cual con distintos objetivos, no existiendo una completa integración entre todos ellos. Los levantamientos indios y las peticiones de la élite protoliberal tenían metas y creencias muy distintas de las de los dirigentes criollos de la élite del movimiento. La ideologia popular estaba inmersa en términos más metafóricos y simbólicos que explícitamente políticos. Las metas de las élites y de gran parte de la rebelión popular no sólo eran distintas entre sí, sino incompatibles.

c) Los antagonismos raciales y sociales asumieron un papel importante en las estructuras mentales del conflicto. Hay que recordar que no casualmente las categorias de indio y campesino se solapaban durante los últimos años de la época colonial. La intensidad del conflicto se alimentó de dicho entrecruzamiento, creciendo a partir del cambio agrario que tuvo lugar a finales del siglo XVIII. La proletarización del campesino indio en partes de México se dio simultáneamente a un proceso de desaculturización.

d) Si es verdad que los cambios agrarios de fines del periodo colonial crearon las precondiciones para un levantamiento masivo y que estos cambios afectaron primordialmente el uso y la propiedad de la tierra, se tendría que caracterizar a los movimientos independentistas como revueltas por la tierra, pero en general éste no parece haber sido el caso. En conjunto, la tierra no parece haber sido una cuestión explícitamente importante en la participación 
campesina, aunque hay que recordar que la lucha por ella ayudó a incrementar la solidaridad dentro del pueblo.

e) El carácter rural de las rebeliones de 1810 , o si se prefiere la ausencia de levantamientos urbanos a gran escala, es, a diferencia del caso europeo, una de las características de los procesos convulsivos mexicanos de comienzos del siglo $\mathrm{XIX}$. Si bien movilizaciones masivas, revueltas, tumultos y linchamientos periódicos azotaron a las provincias de la Nueva España, las principales ciudades del reino permanecieron relativamente tranquilas y, a excepción de Guanajuato y una o dos ciudades más, no experimentaron levantamientos. Esto no quiere decir que las grandes ciudades en otras partes hayan permanecido ilesas durante los diez años de violencia intermitente, ni que no hayan experimentado signos de inquietud interna, sino únicamente que estas perturbaciones asumieron formas distintas a las de la acción masiva colectiva. Las tasas de la migración del campo a la ciudad en muchas partes de la Nueva España fueron bastante altas a fines del período colonial, lo que socavó la propensión de los grupos populares urbanos a embarcarse en acciones colectivas de cualquier tipo, debido a la atomización social que indujo dentro del ambiente urbano. $\mathrm{La}$ estructura del pueblo tradicional, con su visión del mundo centrada en la localidad, proporcionaba un ambiente mucho más propicio para una diferenciación desorganizadora que el medio urbano más atomizado y heterogéneo, y por tanto los contrastes entre el pasado y el presente, tal como los percibian los campesinos que habitaban en los pueblos, pueden haber sido más amenazantes que los acusados por los habitantes de las ciudades y los inmigrantes urbanos recientes. Por último, hay que añadir que los malestares que alimentaron a la rebelión popular eran esencialmente de naturaleza agraria, por lo que no concitaban las simpatias de la población urbana.

f) Reyes indios y milenarismo son dos elementos que no aparecen en las rebeliones indias del centro de México, donde las esperanzas mesiánicas indigenas se centraron en el mismo rey español Fernando VII. Aun cuando no apareció un milenio indio en el norte de México, las conspiraciones y la rebelión en dichas regiones pueden haber estado más cerca del desenlace milenario de lo que estaban las del centro de la Nueva España. En el área central se dio la peculiaridad de un mesías sin milenio. En los paisajes norteños, en que el indio podia encontrarse menos integrado culturalmente, la rebelión y los procesos rebeldes populares tendieron a ser más programáticos en un sentido amplio y a carecer del foco mesiánico sobre la persona del rey español. Las expectativas mesiänicas entre los aldeanos indios de la Nueva España pudo haber funcionado como una potente palanca ideológica en contra de la estructu. 
ra politico-local (funcionarios locales, comerciantes, terratenientes y algunas veces sus propios sacerdotes). El rey de España representaba en cierta forma para los indios la figura proteccionista del padre frente a los abusos de las autoridades locales.

El volumen se termina con una importante contribución teórico-metodológica sobre la historia regional. Se trata de una potente herramienta que nos ayuda a combinar las tensiones entre generalizaciones y particularismos, cuestión fundamental en una realidad como la mexicana, donde la diversidad regional es tan importante. Hasta ahora, siguiendo en buena medida las explicaciones del modelo del sistema dendrítico, que pone el acento en las exportaciones hacia el exterior, se había venido sosteniendo que en el caso de la Nueva España la plata habia sido el elemento central cohesionador de su integración interna. Ello quiere decir, si seguimos esta tesis hasta sus últimas consecuencias, que en los años de mayor producción argentífera, la integración económica interna sería mayor y que ésta se relajaría en los periodos de descenso en las extracciones de metales preciosos. Eric Van Young plantea, sin embargo, que el modelo solar es más apropiado para entender la realidad regional novohispana, salvo escasas excepciones como los casos de Yucatán y Morelos durante algunos períodos de su historia. Si esto es cierto, como parece, se pueden derivar algunas importantes consecuencias teórico-interpretativas. En primer lugar, subraya el autor, deberiamos encontrar mercados de un rango geográfico muy limitado para la mayoria de las mercancias, excepto para aquellas con un alto valor y un reducido volumen como era el caso de los metales preciosos. En segundo lugar, deberiamos hallar bajos niveles de exportaciones regionales para mercancías agricolas; y en tercer lugar, deberíamos encontrar un nivel general bajo de intercambio comercial entre regiones de este tipo. El caso de Guadalajara, estudiado por Eric Van Young, confirma estas suposiciones. Lo que se ve, entonces, al menos en dicho caso y probablemente en otras regiones, es una especie de efecto de iceberg en donde sólo la punta de la economia regional tenia nexos comerciales más amplios, mientras que el resto, si es que estaba comercializado, producia, consumía y comerciaba sólo a un nivel intrarregional.

La importancia de esta nueva interpretación radica en la posibilidad que nos ofrece de entender la dinámica interna virreinal desde nuevos puntos de vista, poniendo en tela de juicio la tesis que sostenía que la profunda integración espacial del virreinato a fines de la época colonial se resquebrajó después de la independencia politica, dando lugar a un fuerte regionalismo y atomización de los mercados internos. Una vez más, comprobamos que la revisión cri- 
tica de los últimos años coloniales nos ayuda a comprender con más exactitud el proceso de formación de la nacionalidad mexicana a comienzos del siglo XIX, facilitándonos el análisis apropiado de' los problemas presentes. Pasado, presente y futuro están entrelazados en un constante diálogo. En un momento como el actual en que México está mirando hacia el futuro intentando redefinir sus bases es de suma utilidad comprender que conceptos tales como «orden» y «progreso» fueron unidos en su momento para justificar posiciones políticas concretas y que tienen, si se aplican sin un rigor crítico a la actualidad, peligrosas consecuencias políticas. Progreso y modernidad no tiene por qué significar obligatoriamente autoritarismo y centralismo. Democracia significa pluralismo.

En resumen, la importancia tanto de las conclusiones explícitas subrayadas por el autor cuanto de aquellos aspectos que quedan enunciados como esquemas de posibles futuras investigaciones, confieren a esta obra un valor innegable dentro de la historiografia mexicanista. La presente edición presenta en un balanceado menú historiográfico las más importantes contribuciones de Eric Van Young, algunas de las cuales fueron en su día artículos en revistas especializadas. El estudioso o simplemente curioso de la historia mexicana tiene la ventaja ahora de ver reunidos y traducidos unos materiales antes en ciertos casos de difícil acceso. El especialista puede encontrar la completa evolución del pensamiento histórico de Eric Van Young, además de novedades editoriales como es el capítulo segundo titulado «Los ricos se vuelven más ricos y los pobres más pobres; salarios reales y estándares populares de vida a fines de la colonia en México». El análisis local de los precios y de los salarios; la estructura regional y análisis de los mercados internos; los desajustes de la vida colonial, el mesianismo y la revuelta popular, pasando por el estudio de las relaciones ciudad-campo, son temas que se van integrando sucesivamente de forma coordinada. La última parte relativa a las consideraciones metodológicas y teóricas supone una excelente conclusión del presente libro, al brindar al lector una reflexión teórica y metodológica sumamente útil para continuar estudiando el pasado de México.

Con seguridad que la lectura de este texto abrirá nuevas perspectivas de investigación, y lo que es más importante, creará nuevas inquietudes. $\mathrm{Si}$, como se suele decir, la historiografia, debido a la enorme masa de materiales que tiene que mover y a la constante diferente visión del pasado de cada época, camina lentamente, es evidente que con este libro hemos adelantado varios tramos de una sola vez. 